\title{
Zoospores of the Oyster Pathogen, Dermocystidium marinum. I. Fine Structure of the Conoid and Other Sporozoan-Like Organelles
}

Frank O. Perkins

Virginia Institute of Marine Science

Follow this and additional works at: https://scholarworks.wm.edu/vimsarticles

Part of the Marine Biology Commons

\section{Recommended Citation}

Perkins, Frank O., Zoospores of the Oyster Pathogen, Dermocystidium marinum. I. Fine Structure of the Conoid and Other Sporozoan-Like Organelles (1976). Journal of Parsitology, 62(6), 959-974. https://scholarworks.wm.edu/vimsarticles/1991 


\title{
ZOOSPORES OF THE OYSTER PATHOGEN, DERMOCYSTIDIUM MARINUM. I. FINE STRUCTURE OF THE CONOID AND OTHER SPOROZOAN-LIKE ORGANELLES*
}

\author{
Frank O. Perkins \\ Virginia Institute of Marine Science, Gloucester Point, Virginia 23062
}

ABSTRACT: An apical complex comparable to that found in the Sporozoa is described from zoospores of Dermocystidium marinum Mackin, Owen, and Collier, a pathogen of the American oyster (Crassostrea virginica Gmelin). The complex consists of a conoid, polar ring, up to 39 subplasmalemmal microtubules, rhoptries, and micronemes. Micropores and a subpellicular membrane equivalent were also found. Acid phosphatase activity was found in cisternae of the endoplasmic reticulum, inclusion bodies, and vesicles within the conoid lumen. No polysaccharides were detected in the rhoptries and micronemes using the Thiéry method. Observations indicate that $D$. marinum is a protozoan in the subphylum Apicomplexa and is most closely related to the coccidian Sporozoasida Leuckart.

Since the initial description by Gustafson et al. (1954), numerous authors have noted that coccidians, gregarines, Sarcocystis sp., Besnoitia sp., and Frenkelia sp. all have, in one or more cell stages in the life cycle, a hollow, cone-like structure at the anterior end of the cell. This organelle, termed a conoid, consists of tubular subunits, spirally arranged to form a truncated hollow cone $0.08 \mu \mathrm{m}$ to $0.4 \mu \mathrm{m}$ in diameter at the anterior end and $0.2 \mu \mathrm{m}$ to 0.53 $\mu \mathrm{m}$ at the posterior end (Scholtyseck, 1973).

Anterior to the conoid are 2 (possibly 3: Porchet-Henneré, 1975) preconoidal rings consisting of electron-dense granular material connected to the conoid by a canopy of electron-dense material which has an opening at the extreme anterior end. A ring of electrondense material, the polar ring, encircles the conoid. The ring is an anterior elaboration of the two closely opposed unit membranes ("subpellicular membrane") which lie slightly under the plasmalemma. Two or more flaskshaped, membrane-bound sacs of electrondense material converge on the conoid, the neck of each "flask" lying within the conoid lumen. These structures, termed rhoptries or paired organelles, are believed to contain lytic enzymes which aid the organism in host cell penetration. Scattered throughout the anterior $1 / 2$ or $1 / 3$ of the cell are the micronemes which are cord-like, membrane-bound sacs of electron-dense material. Some workers have suggested the rhoptries and micronemes are

Received for publication 26 January 1976.

* Contribution No. 786, Virginia Institute of Marine Science, Gloucester Point, Virginia 23062. one functional system, possibly the latter giving rise to the former (Vivier and Petitprez, 1972).

Attached to and radiating from the polar ring are generally 22 to 24 microtubules which lie beneath the "subpellicular membrane" and extend most of the distance toward the cell posterior. In most of the organisms with conoids are also found 1 to 9 invaginations of the plasmalemma, the micropores. These specialized structures often have a collar of electron-dense material around the distal part of the invagination and another outer cylindrical collar formed by infolding of the "subpellicular membrane." The latter is discontinuous at the proximal end of the invagination.

Collectively the conoid, polar ring, subpellicular microtubles, micronemes, and rhoptries have been termed the apical complex (Levine, 1973). The consistency with which the complex has been observed in Protozoa that appear to be related for other reasons, has led to the construction of the subphylum Apicomplexa Levine 1970, which includes the piroplasms, gregarines, and coccidians. The latter group includes species of Toxoplasma, Sarcocystis, Besnoitia, Plasmodium, Frenkelia, Eimeria, and Isospora.

In this paper it is shown that the oyster pathogen, Dermocystidium marinum, also has the organelles described above and thus has affinities with the Apicomplexa. There are numerous suggestions in the literature as to the affinities of the pathogen, ranging through such diverse groups as the Rhinosporidiaceae 
of the Endomycetales (Mackin, 1962), Synchytriaceae of the Chytridiales (Mackin and Boswell, 1956), Labyrinthulia (Mackin and Ray, 1966), Ascomycetes (Mackin, 1951), Haplosporida (Sprague, 1954), and Entomophthorales (F. K. Sparrow, Jr. in Ray, 1954). Mackin and Ray (1966) have renamed the organism Labyrinthomyxa marina thus considering it to be allied to the Labyrinthulia. Their decision resulted from observations of gliding cells with labyrinthulid "tracks," plasmodia, and vegetative division figures similar to those of Labyrinthomyxa sauvageaui (Duboseq 1921). Perkins (1974) did not find any labyrinthulid characteristics in the oyster pathogen, except an unusual kinetosome granule, and expressed the opinion that D. marinum could not, at that time, be related to any known group of organisms.

\section{MATERIALS AND METHODS}

Infected oysters (Crassostrea virginica) were obtained from the York River and maintained in aquaria at ca. 25 C. Zoosporulation was induced using techniques described by Perkins and Menzel (1967), except that natural estuarine water was used throughout the procedure, not Cameron's seawater. Fixation of zoospores was accomplished for $30 \mathrm{~min}$ to $1 \mathrm{hr}$ in $2.5 \%(\mathrm{w} / \mathrm{v})$ glutaraldehyde buffered at $\mathrm{pH} 7.2$ to 7.4 in $0.1 \mathrm{M}$ sodium cacodylate or $0.1 \mathrm{M}$ Millonig's phosphate buffer at ca. $24 \mathrm{C}$. Four buffer rinses over a $60 \mathrm{~min}$ period preceded postfixation with $1 \% \mathrm{OsO}_{4}$ in one of the above buffers with $0.2 \mathrm{M} \mathrm{NaCl}$. Postfixation was for 3 $\mathrm{hr}$ at ca. $24 \mathrm{C}$. Before dehydration in a graded ethyl alcohol series, cells were held in $2 \%$ aqueous uranyl acetate for $60 \mathrm{~min}$. Embeddings were in Durcupan ACM (Fluka) or Epon 812. Sections were stained for $15 \mathrm{~min}$ in $2 \%$ uranyl acetate prepared in $35 \%$ ethyl alcohol followed by $5 \mathrm{~min}$ in Reynold's lead citrate.

For three dimensional studies, serial sections were mounted on a Formvar substrate on Mason and Morton slot $(2 \times 1 \mathrm{~mm})$ discs. Reconstructions of zoospore structures were then made by tracing cell and organelle profiles on clear acrylic plastic sheets (Flex-O-Glaze, Warp Brothers, Chicago, III.). Cell profiles were then cut out and glued together in proper sequence to yield a model of the cell surface topography in which could be seen relative positions of organelles.

Assessments and presentations of mature zoospore structure were based on observations of zoospores which were swimming free of the zoosporangium at the time of fixation. Although micrographs are presented from intrasporangial zoospores, all figures represent fully mature and differentiated structures.

Whole mounts of ruptured zoospores were pre- pared on Formvar-coated grids by suspending a pellet of zoospores in distilled water, picking up the ruptured cells in a nichrome wire loop, placing the loop on the surface of distilled water, and touching the grid to the water's surface within the wire loop. Grids were then stained on drops of $2 \%$ aqueous uranyl acetate for 1 to $5 \mathrm{~min}$. The few cells which spread on the surface of the water had fewer cytoplasmic fragments attached to the conoid and cytoskeleton than zoospores prepared by any of the other methods tried, such as those of PorchetHenneré (1975), Ryley (1969), and Angelopoulos (1970). Dehydration of the ruptured zoospores by ethyl alcohol did not result in better visualization of the cytoskeleton and conoid nor did rupture and extraction on the surface of $10 \%(\mathrm{v} / \mathrm{v})$ aqueous triton X-100 or $12 \%(\mathrm{w} / \mathrm{v})$ aqueous hexylene glycol.

Modified Gomori's cytochemical techniques (Kazama, 1973) were used to detect acid phosphatase. Craig's (1974) periodic acid-thiocarbohydrazide-silver proteinate cytochemical techniques modified from Thiéry (1967) were used to detect polysaccharides. Sodium borohydride was used as an aldehyde blocking agent.

\section{RESULTS}

The conoid of Dermocystidium marinum zoospores consists of a sheet of 17 to $20(\overline{\mathrm{x}}=$ $18 ; \mathrm{N}=12$ ) microtubules coiled into an opensided, truncated cone (Figs. 1-8). At the anterior end, the sheet forms either a complete or nearly complete circle (Figs. 3, 7). Posteriorly the sheet opens to a $180^{\circ}$ curve (Figs. $4,7)$. The microtubules are approximately in parallel array and are obliquely oriented to the longitudinal axis of the cone, forming angles of inclination ranging from $50^{\circ}$ to $88^{\circ}$ ( $\mathrm{N}=$ 16) depending upon where the measurement is made; the tilt being more pronounced distally than proximally (Fig. 8).

Three or four of the conoid microtubules extent 0.26 to $0.66 \mu \mathrm{m}(\overline{\mathrm{x}}=0.45 ; \mathrm{N}=11)$ beyond the truncated cone (Figs. 2, 7, 8, 17). Attached to the longer microtubules is a single row of 16 to 21 ( $N=6$ ) vesicles or membranebound bulbous terminations ( 25 to $33 \mathrm{~nm}$ diameter; $\bar{x}=30 ; N=14$ ) of micronemes, herein termed conoid-attached micronemes (CAM). The CAM are graded in length, those attached to the region of the microtubules most distal to the conoid being the longest and those furthest into the conoid lumen being simple vesicles (Figs. 7, 10). The former follow a wavy course diagonally across the cell width, then terminate in the posterior fourth of the cell, 


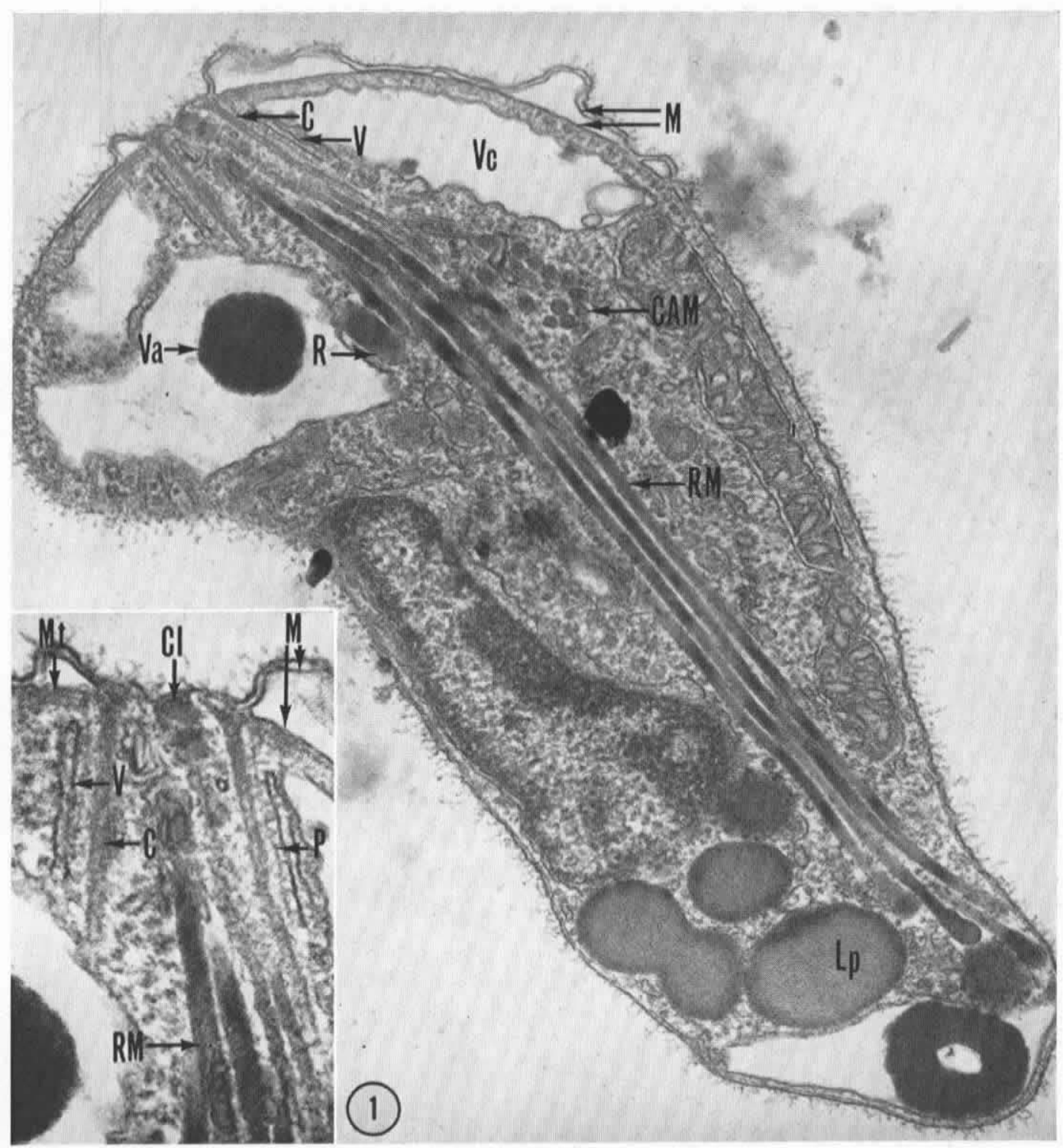

Figures 1-19. Electron micrographs and drawings of Dermocystidium marinum zoospores. Figures $8,11,12$, and 18 are from negatively-stained fragments of ruptured zoospores. Abbreviations: C, conoid; CAM, conoid attached micronemes; CI, membrane-bound inclusions in conoid lumen; D, distal end of of conoid; EM, extended microtubules of conoid to which are attached micronemes; G, granular layer analogous to subpellicular membrane; K, kinetosome; L, labyrinthine complex; LD, lead depositions indicative of acid phosphatase; Lp, lipoid inclusion bodies; $\mathbf{M}$, membranes of flattened vesicles homologous to subpellicular membrane; MC, microtubules of conoid; Mt, subplasmalemmal microtubules; P, polar mantle; PR, polar ring; Po, posterior ring; R, rhoptry; RM, rectilinear micronemes; T, terminations of micronemes on microtubules of conoid; V, conoid-associated vesicle of endoplasmic reticulum; Va, vacuoplast; Vc, large anterior vacuole. 1, 2. Longitudinal, medial sections of zoospores. Fig. 1 inset is higher magnification of conoid in Fig. 1. Fig. 1: $\times$ 50,000; Fig. 1 inset: $\times 90,000$; Fig. 2: $\times 134,000$. 3, 4. Cross sections of a single apical complex showing distal (Fig, 3) and proximal (Fig. 4) ends of conoid. Micrographs are from ca. $60 \mathrm{~nm}$ thick sections, numbers 1 and 8 of a series. Note that microtubules of conoid collectively circumscribe a $295^{\circ}$ angle at the distal end and a $180^{\circ}$ angle at the proximal end. Both Figs.: $\times 74,000$. 5-7. Diagrams of apical complex in longitudinal (Fig. 5 ) and anterior, frontal (Fig. 6) views. Figure 7 shows conoid substructure with polar ring, attached subplasmalemmal microtubules, and polar mantle. Limits of the latter are indicated by coarse, widely spaced dots. 


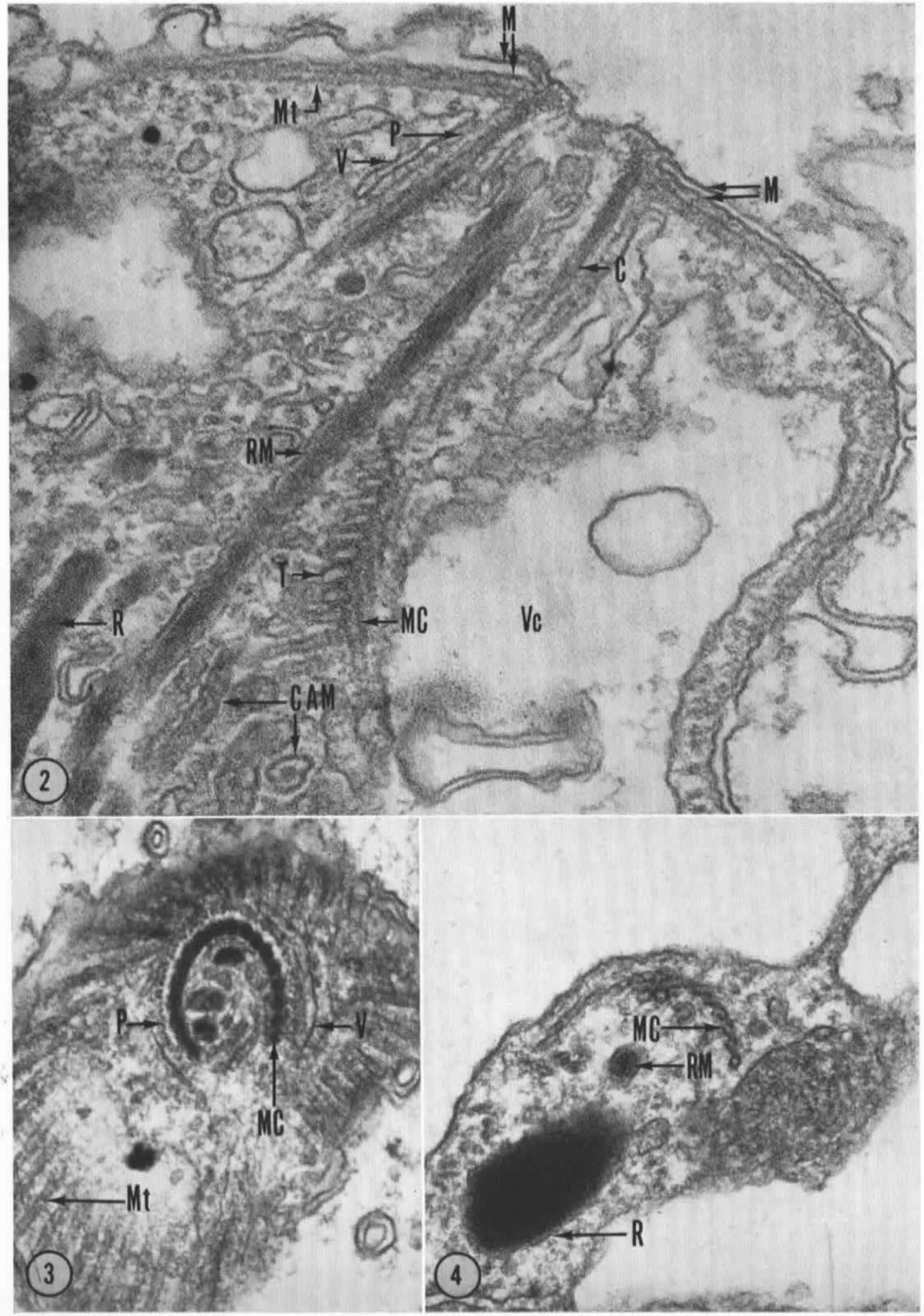



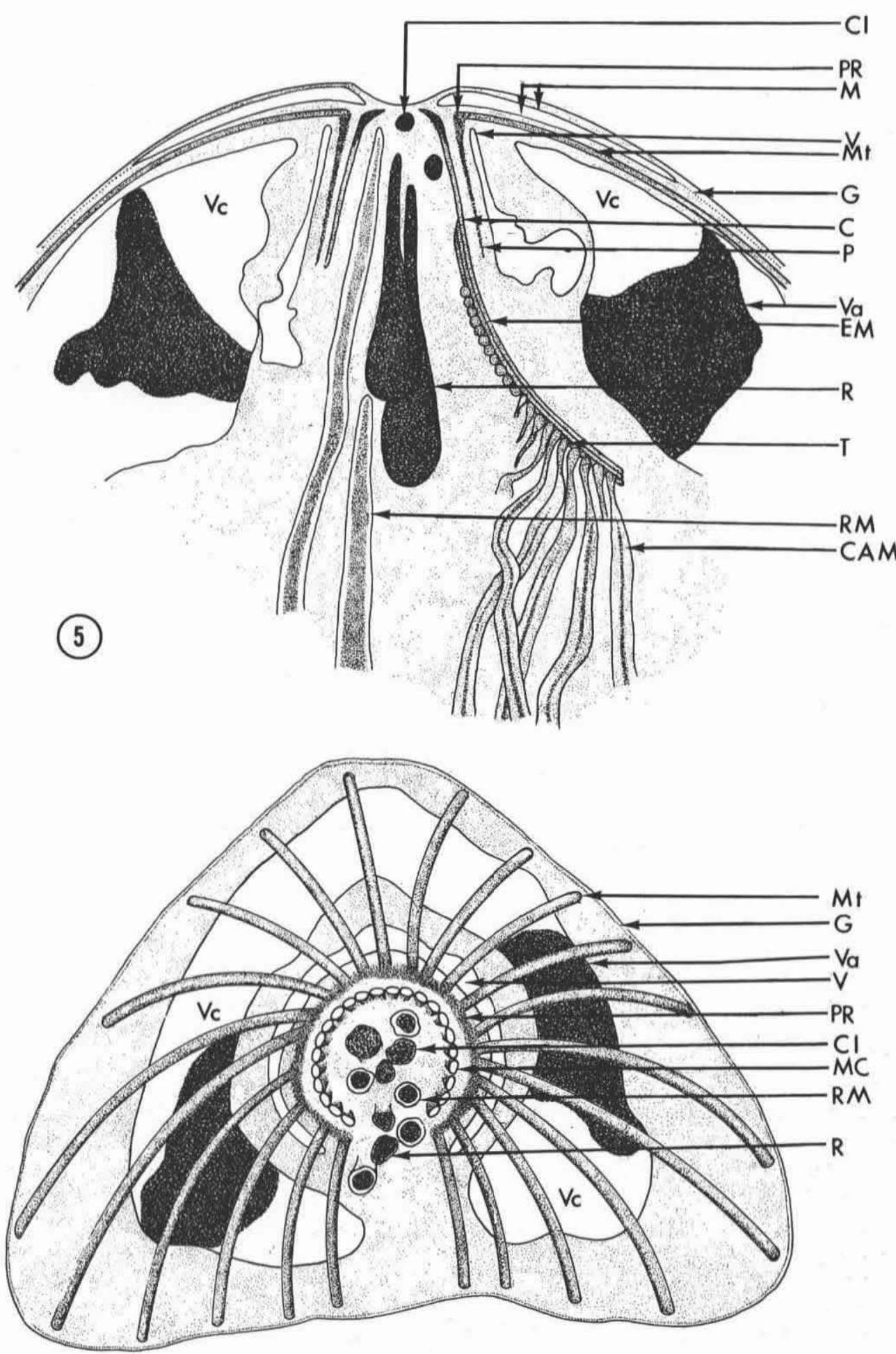

(6) 


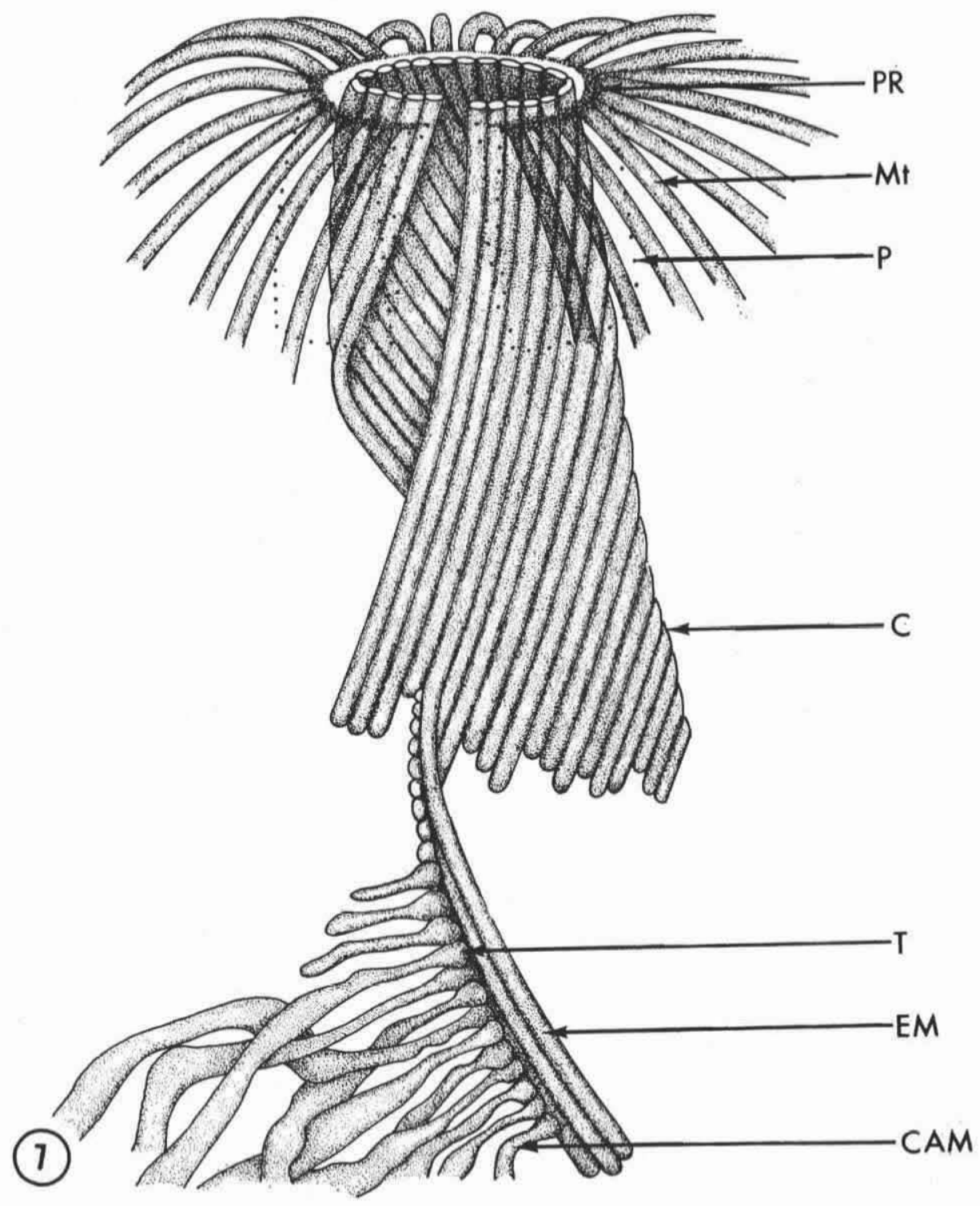

traveling beneath the cell surface on the side of the cell opposite the flagellar attachment points (Fig. 9). The CAM contain electrondense material organized into a dense core and a lighter medulla. Excluding the bulbous terminations, the cross sectional diameters of the CAM vary from a mean of $19 \mathrm{~nm}(\mathrm{~N}=17$; range $=16$ to 24 ) near the conoid to a mean of $42 \mathrm{~nm}(\mathrm{~N}=23$; range $=37$ to 45$)$ along most of the length. Microtubules comprising the conoid are 17 to $26 \mathrm{~nm}$ in diameter [ $\mathrm{N}=$ $\left.24 ; \overline{\mathrm{x}} \pm\left(\mathrm{S}_{\mathrm{s}}\right)\left(\mathrm{t}_{0.05}\right)=22 \pm 1\right]$ and have a fluid filled core as evidenced by entry of negative stain into the lumen. The negativelystained microtubules have a typical substructure consisting of strands of spherical subunits in parallel array, arranged around the microtubule lumen.

The overall dimensions of the conoid are: (1) anterior-end width 0.13 to $0.25 \mu \mathrm{m}(\overline{\mathrm{x}}=$ $0.20 ; \mathrm{N}=13$ ); (2) posterior-end width 0.18 to $0.34 \mu \mathrm{m}(\overline{\mathrm{x}}=0.25 \mu \mathrm{m} ; \mathrm{N}=12)$; (3) length (not including the three microtubular extensions) 0.21 to $0.33 \mu \mathrm{m}(\overline{\mathrm{x}}=0.29 ; \mathrm{N}=$ 
12); and (4) length (including microtubular extensions) 0.57 to $0.96 \mu \mathrm{m}(\overline{\mathrm{x}}=0.75 ; \mathrm{N}=$ 12).

Encircling most of the conoid is a mantle of granular material with the anterior-most portion forming a functional polar ring to which are attached subplasmalemmal microtubules (Figs. 1-3, 5-7, 11, 12, 17). Sectioned cells contain no evidence of a ring, showing only microtubular termination at the anterior-most end of the granular mantle (Figs. 3, 17) whereas negatively-stained preparations show an obvious ring (Figs. 11, 12) with attachment of microtubules to the ring (Fig. 11). Although there was no clear delineation in negativelystained cells, the polar ring and conoid microtubules appeared to be separate entities. In sectioned cells subplasmalemmal microtubules were never clearly seen to attach to the conoid. Therefore, the polar ring as seen in Figs. 11 and 12 is considered to be part of the granular mantle since the ring could not be part of any other structure as determined from observations of sectioned cells. No pre-conoidal rings were observed.

Up to 39 microtubules have been observed attached to the polar ring in negatively-stained whole mounts of ruptured zoospores and in sectioned zoospores; however, the range of values ( 20 to 39 ) was too broad and the values too closely spaced to determine a precise number, if there is in fact, a fixed number of microtubules. From the termination of the microtubules on the granular ring (Fig. 11), they radiate and follow a pathway beneath an overlying, flattened vesicle (Figs. 2, 17) to its termination, then follow a path about $10 \mathrm{~nm}$ beneath the plasmalemma to the posterior end of the cell. Only about 10 microtubules extend to the extreme posterior end where there is a granular ring about $0.30 \mu \mathrm{m}$ outside diameter (Fig. 13). No microtubules were seen attached to the ring.

Below the anterior polar ring and paralleling the granular mantle is a flattened vesicle of the endoplasmic reticulum (ER) (Figs. 5, 6, $10,13)$. The vesicle parallels the granular mantle and conoid being discontinuous where they are incomplete (Fig. 6).

In addition to the CAM, there is a bundle of about 20 membrane-bound sacs filled or nearly filled with electron-dense material (Figs.
$1,2,9,10,15)$, herein referred to as rectilinear micronemes (RM). They differ from the CAM in that the contents are more electron-dense and the profiles are nearly straight, most of them extending from the conoid to the posterior $10 \%$ of the cell. Cross sectional diameters are the same in the two classes of sacs (Fig. 15), the RM type having a mean of $42 \mathrm{~nm}$ (range: 35 to $49 ; \mathrm{N}=11$ ). Anteriorly, a few of the micronemes taper to blunt tips within the conoid lumen, extending within $50 \mathrm{~nm}$ of the plasmalemma which overlies the conoid lumen but not connecting to it (Fig. 2). Most of the RM terminate posterior to or to one side of the conoid. The tip contents are generally more electron-lucent than the more posterior regions of the sacs. Posteriorly, the micronemes have bulbous terminations.

Three to ten rhoptries consisting of membrane-bound, electron-dense material are found in the anterior half of the cell with the necks of the sacs extending into the conoid lumen or along the outside of the conoid (Figs. 1, 15, 17). Those within the conoid have anterior terminations in the posterior half of the lumen, not near the plasmalemma which overlies the conoid. Total length of the rhoptries ranges from 0.5 to $1.6 \mu \mathrm{m}$. Membrane-bound, electron-dense inclusions were infrequently found in the conoid lumen (Figs. 1 inset, 14). They resembled the rhoptries in density and granularity; however, neither budding from the rhoptries nor rhoptry fragmentation was identified.

Nearly surrounding the apical complex is a U-shaped vacuole (Figs. 1, 5, 6, 17) containing amorphous, electron-dense material identi$\mathrm{cal}$ in fine structure to the vacuoplasts of vegetative stages (Perkins, 1969). The complex is situated in a ridge of cytoplasm which extends through the vacuole. All of the discontinuities in the subunits of the complex (the conoid, flattened vesicles, and polar ring) face the surface along which the ridge is attached to the cell body (Fig. 6).

Between the subplasmalemmal microtubules and the plasmalemma is a labyrinthine network seen in most sections as a discontinuous, thin, electron-dense layer (Figs. 16, 17) which is 1.5 to $4.2 \mathrm{~nm}$ thick $\left(\overline{\mathrm{x}} \pm \mathrm{S}_{\mathrm{s}}\left(\mathrm{t}_{0.05}\right)=2.5 \pm\right.$ $0.19 ; N=20)$. In negatively-stained whole mounts the labyrinthine substructure of the 
layer can be seen (Fig. 18), a characteristic which is not visible in sections tangential to the cell surface as seen by Aikawa and Sterling (1974). The layer enrobes the cytoplasm except at the anterior end where there is a Ushaped flattened vesicle overlying the large vacuole containing vacuoplast material (Figs. $1,2,5,17)$. The thin labyrinthine layer terminates on the posteriormost portion of the flattened vesicle (Figs. 16, 17). Aplanospores (trophozoites) of D. marinum do not form the thin layer.

A single micropore (micropyle) is found at the posterior end of the zoospore, consisting of a 0.10 to $0.15 \mu \mathrm{m}$ deep, flask-shaped sac formed by plasmalemmal invagination. A collar of electron-dense material surrounds most of the invagination (Fig. 19). Continuity of the collar with the labyrinthine layer mentioned above has not been observed.

Gomori's method for acid phosphatase localization revealed activity in three organelles: lipoid inclusion bodies in the posterior end of the cell (Fig. 1), cisternae of the endoplasmic reticulum, and membrane-bound spheroidal inclusions in all regions of the conoid lumen as well as slightly posterior to the lumen (Fig. 14). In sections not treated by Gomori's method, the latter inclusions most closely resemble rhoptries in terms of electron density and granularity. They were found frequently in Gomori's preparations, but rarely in other sectioned cells. Possibly the inclusions arose from fragmentation of rhoptries during fixation. It is known that the low concentration of glutaraldehyde (1\%) did permit zoospore encystment and flagellar retraction in one preparation which was later discarded and not used in assessing enzyme activity. Possibly other organelle changes occurred. Micronemes and structures recognized to be rhoptries contained no acid phosphatase activity.

No polysaccharides were detected using the modified Thiéry periodic acid-thiocarbohydrazide-silver proteinate method.

\section{DISCUSSION}

Although differences (see below) exist between the apical complex of Dermocystidium marinum zoospores and any given species of the Apicomplexa, I believe the basic structure of the oyster pathogen's complex is well within the range of structural variation observed in the Apicomplexa (Scholtyseck, 1973; Schrevel, 1968 ). For example there is clearly more variation between the Gregarinasina Dufour 1828 and Piroplasmasida Levine 1961 or even between the Coccidiasina Leuckart 1879 and the Gregarinasina than between D. marinum and the Coccidiasina (Schrevel, 1968; Scholtyseck, 1973; Aikawa and Sterling, 1974).

With the demonstration of an apical com-

Figunes 8-19. Dermocystidium marinum cont'd. 8. Uranyl acetate-stained whole mount of conoid from ruptured zoospore showing terminations of conoid-attached micronemes. Note intrusion (unlabeled arrow) of negative stain into conoid microtubules. Angle of inclination of conoid microtubules is greater at distal than proximal end. $\times 100,000$. 9. Longitudinal section of zoospore showing rectilinear and conoid-attached micronemes extending nearly the full length of the cell. $\times 36,000,10$. Apical complex in longitudinal section. $\times 140,000$. 11, 12. Uranyl acetate-stained whole mounts of conoids and subplasmalemmal microtubules from ruptured zoospores. Note attachment of microtubules to ring portion of polar mantle in Fig. 11 (unlabeled arrow). Fig. 11: $\times 240,000$; Fig. 12: $\times 150,000$. 13. Posterior ring of zoospore. Microtubules (unlabeled arrows) approach, but do not attach to ring. $\times 48,000$. 14. Zoospore after incubation in modified Gomori's medium used to detect acid phosphatase activity. Conoid inclusions show evidence of acid phosphatase whereas the rhoptry and rectilinear microneme do not, with the possible exception of one region of the rhoptry (indicated by "LD"). Normally rhoptries contain no evidence of acid phosphatase, but are believed to give rise to the conoid inclusions. $\times 110,000$. 15. Cross section of zoospore at level of kinetosomes (see Fig. 9) showing rhoptries and two types of micronemes. Note subplasmalemmal microtubules. $\times 54,000,16,17$. Flattened vesicle membranes homologous to subpellicular membrane of apicomplexan Protozoa. Granular layer which is analogous to the subpellicular membrane is attached to flattened vesicle (unlabeled arrows). Fig. 16: $\times$ 137,000; Fig. 17: $\times 76,000$. Inset contains high magnification of polar ring region showing convergence and terminations of polar mantle and subplasmalemmal microtubule. $\times 123,000$. 18. Uranyl acetate-stained, ruptured zoospore showing labyrinthine complex beneath plasmalemma. Complex is believed to be same as granular layer seen in Figs. 16 and $17 . \times 145,000$. 19. Micropore (unlabeled arrow) in posterior end of zoospore. Note electron-dense granular collar around mid-region of invagination. $\times 117,000$ 

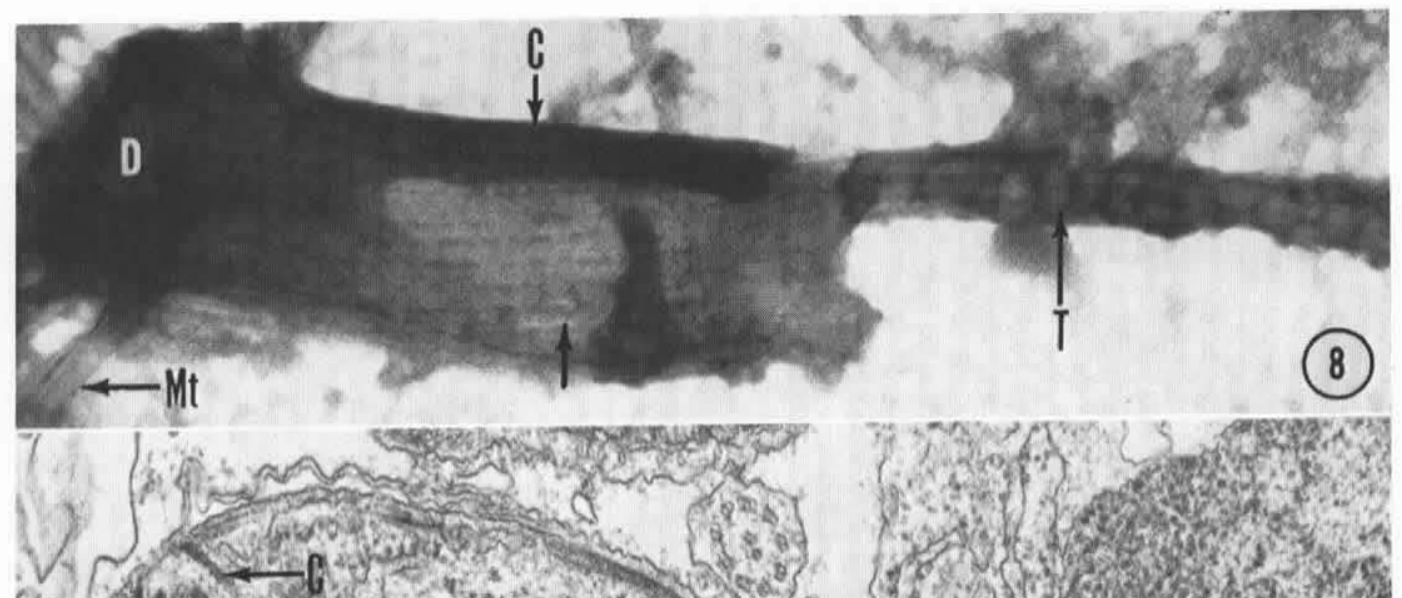

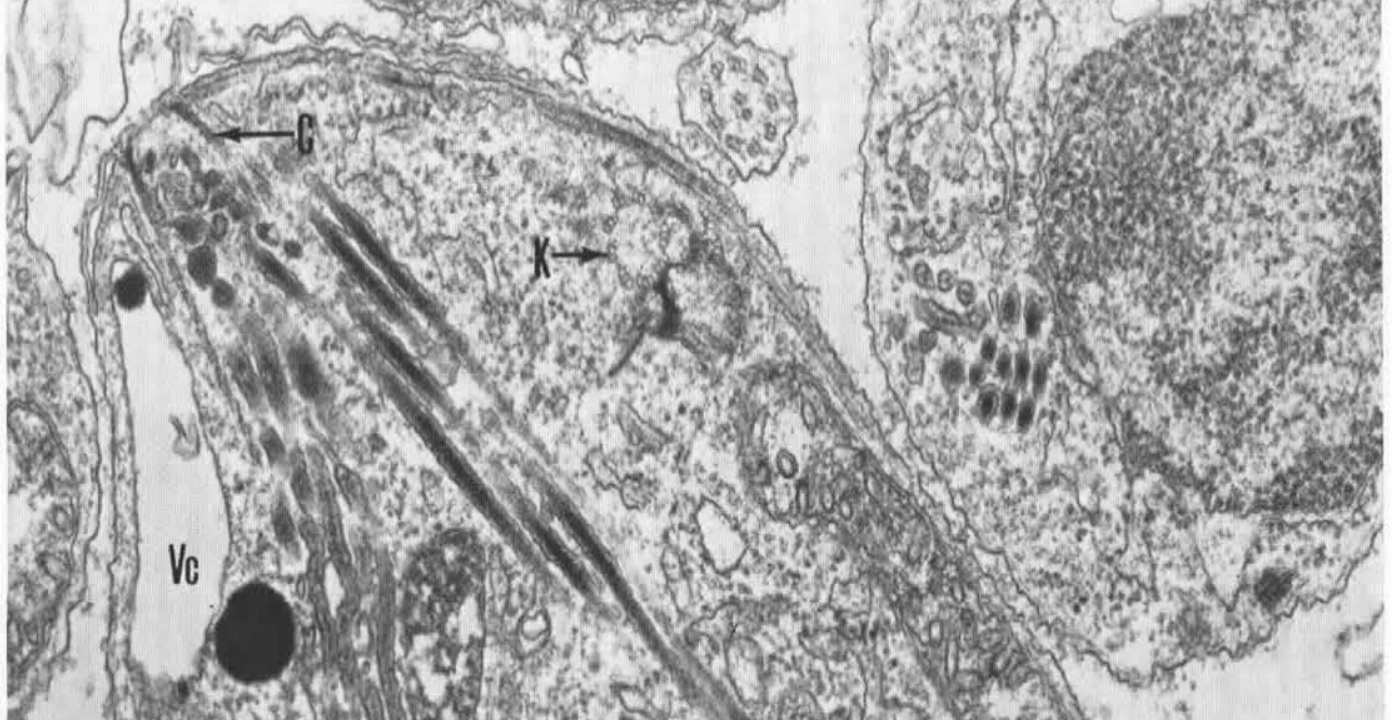
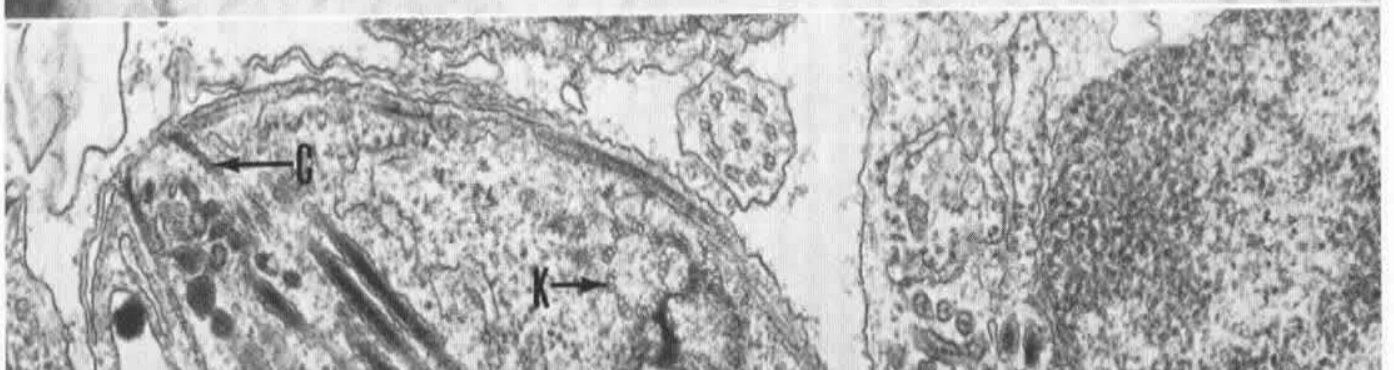

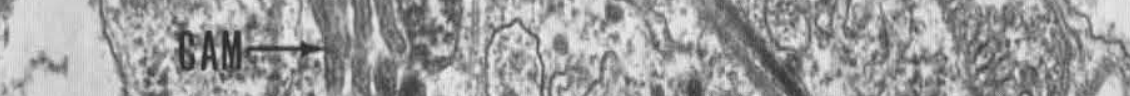

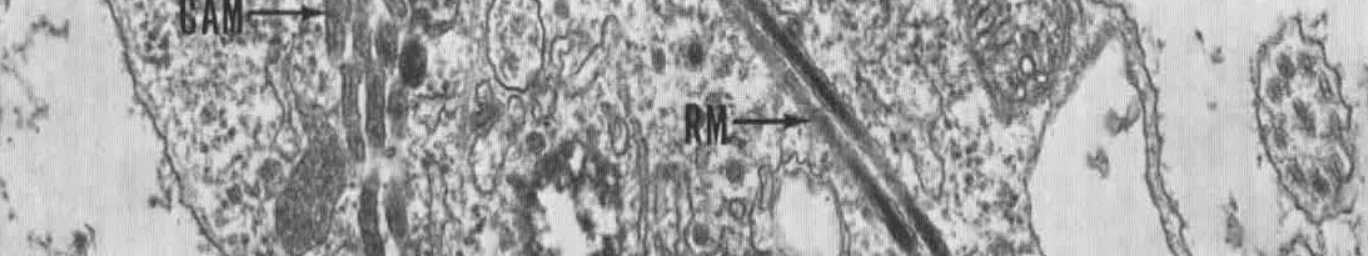
4., for

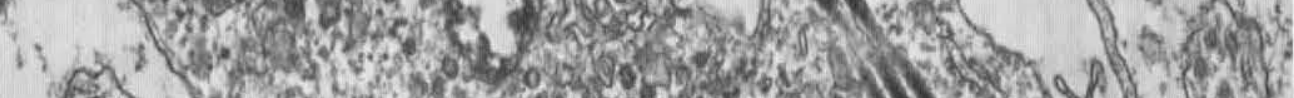

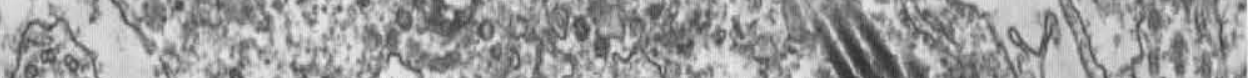
(8)

4 - (20)

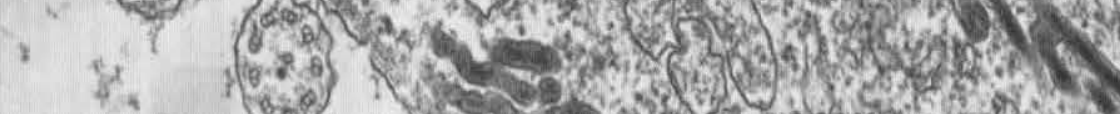

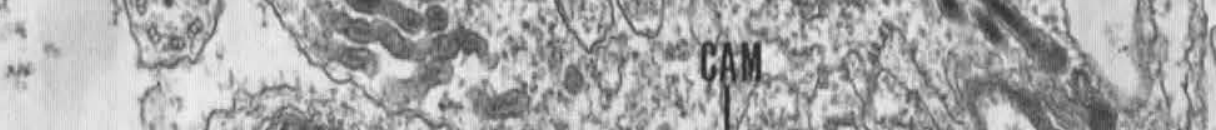

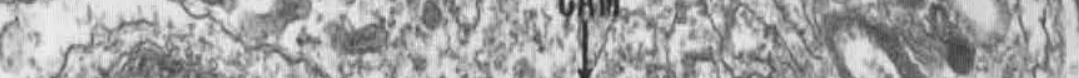
8. 1 (1)

(9) 4 (6) 






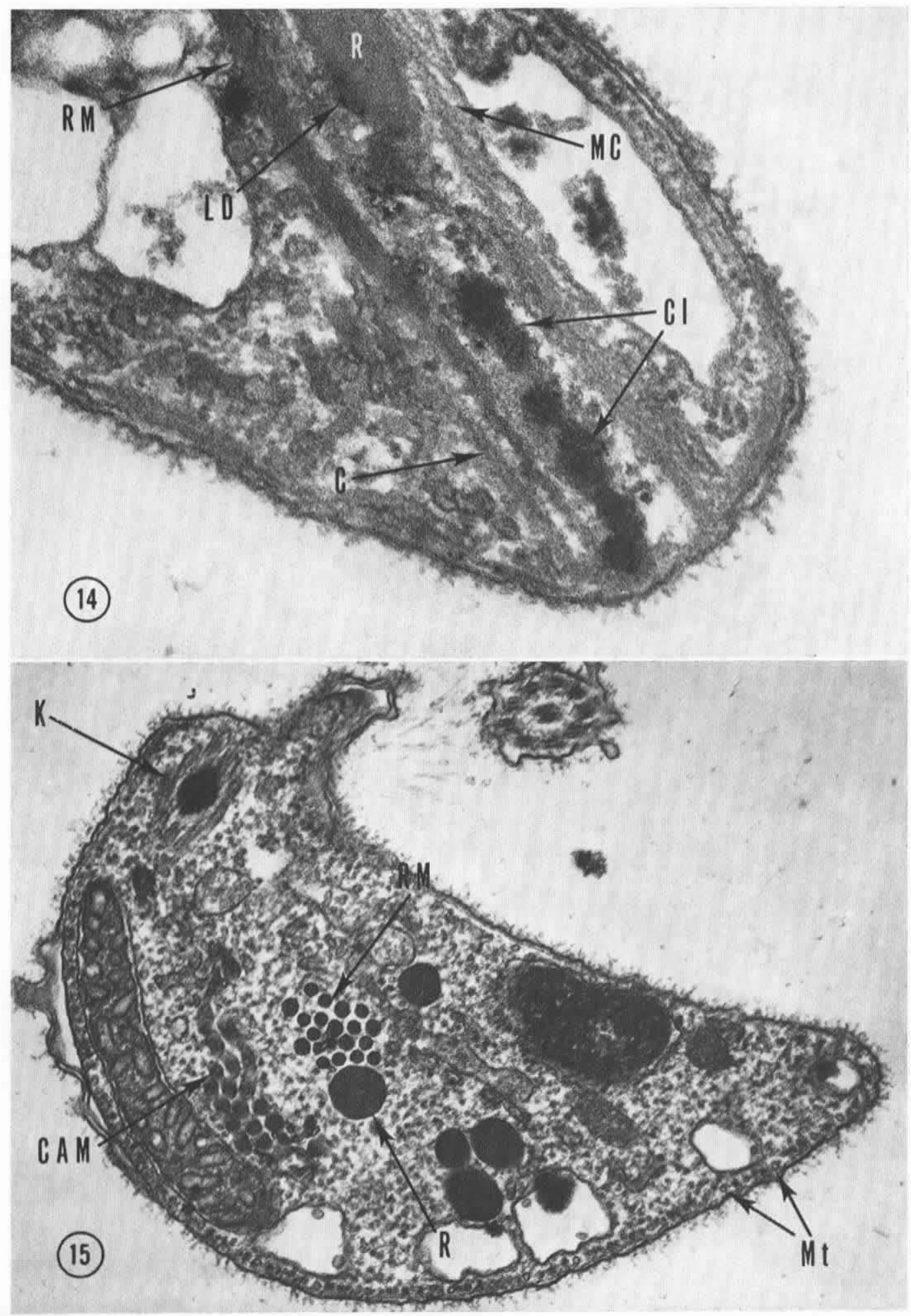

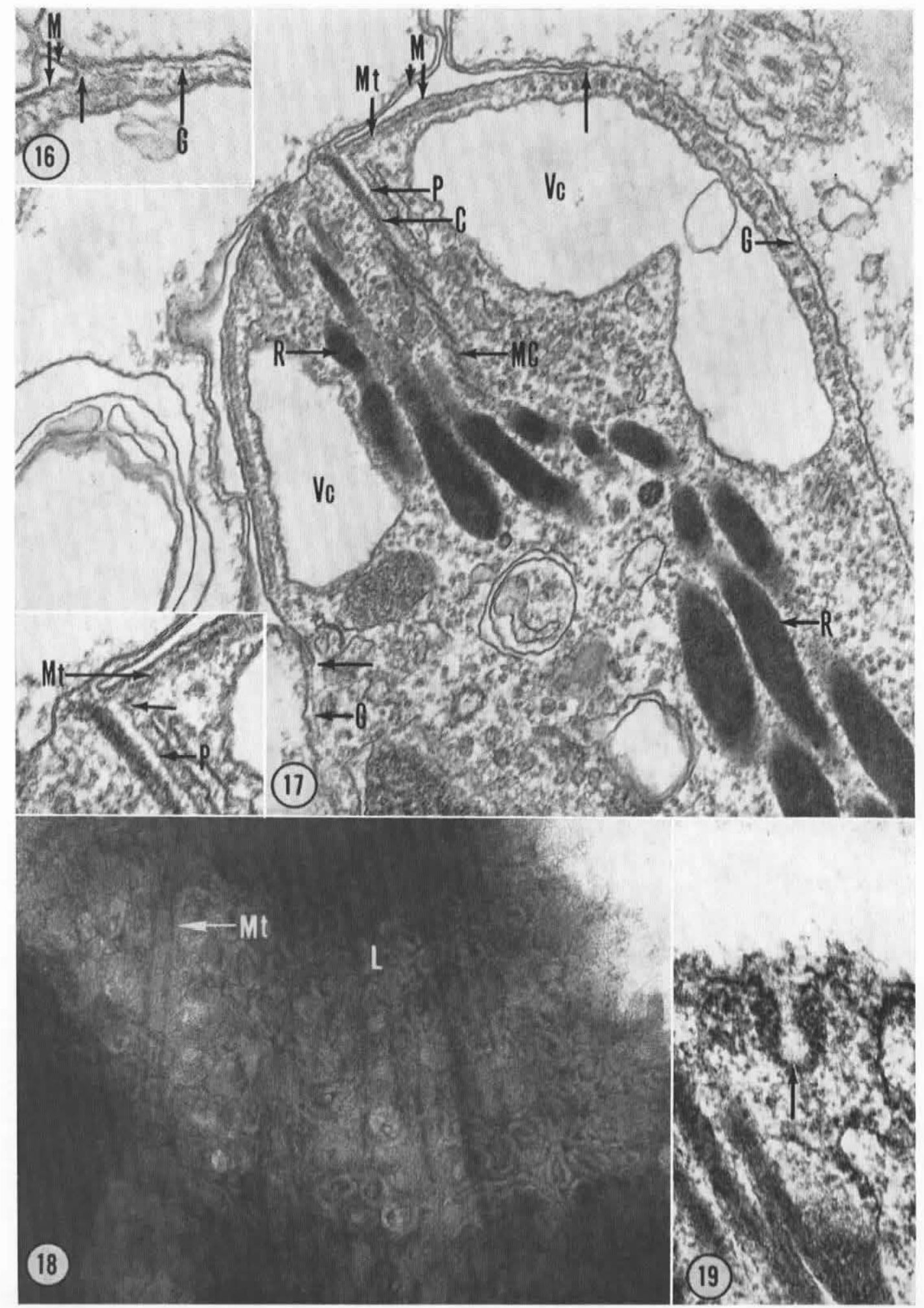
plex in D. marinum zoospores, the question arises: are apical complexes truly unique organelle groupings or do they have a wider phylogenetic range than formerly thought? I believe the organelle complex can still be considered unique to the Apicomplexa. A considerable number of Protozoa (Grell, 1973), algae (Dodge, 1973; Pickett-Heaps, 1975), and fungi (Madelin, 1966; Perkins, 1976; Bracker and Littlefield, 1973) have been examined ultrastructurally and only the Sporozoasida Leuckart 1879 and Piroplasmasida had been shown to possess an apical complex prior to this study. Furthermore there are several additional reasons for including $D$. marinum in the Apicomplexa. In addition to the apical complex, zoospores and trophozoites of the oyster pathogen possess micropores (Perkins, 1969), zoospores have a subpellicular-like, labyrinthine layer between the plasmalemma and subplasmalemmal microtubules, and the species is parasitic, all of which are characteristics of the Apicomplexa.

There are, however, differences from other members of the Apicomplexa. D. marinum lacks sporozoan schizogony, endodyogeny, and endopolyogeny in its life cycle, forming daughter cells by progressive cleavage of a multinucleated protoplast or by successive bipartition of the protoplast (Perkins, 1974). Scholtyseck (1973) has suggested that endodyogeny is a fundamental type of cell division in the Sporozoa (Apicomplexa of Levine, 1970). Schizogony and endopolyogeny are also characteristic of the Apicomplexa (Aikawa and Sterling, 1974). Progressive cleavage could be considered as a modification of schizogony in that cleavage is initiated from the periphery and progresses centripetally; however, there is no involvement of a subpellicular membrane nor is there a residual body left after cleavage as in most sporozoans (Aikawa and Sterling, 1974). Successive bipartition (alternating karyokineses and cytokineses) does not occur in the Apicomplexa (Grell, 1973; Scholtyseck, 1973). D. marinum forms biflagellated zoospores with an anterior flagellum possessing mastigonemes. Such accessory structures have not been observed on flagellated cells of other species in the Apicomplexa. Moreover, the flagellated cells of apicomplexans are microgametes, not zoospores. There is no evidence that flagellated cells of the oyster pathogen are a product of meiosis or that they participate in copulation-isogametic or heterogametic.

D. marinum zoospores in the absence of any other cell type can initiate infections in oysters. Although quadriflagellate zoospores have been observed, they are rare and are suspected to be the result of incomplete cytokinesis, not copulation, since they are not numerous enough to account for the number of infection sites initiated in oysters (Perkins, unpubl. data).

In spite of the differences cited above, I suggest that the presence of: (1) an apical complex, (2) a subpellicular layer probably analogous to the subpellicular membrane (see discussion below), and (3) micropores all indicate that $D$. marinum is one of the Apicomplexa. The presence of a conoid and the absence of a digestive vacuole associated with the conoid further indicates that affinities are closest to the coccidians, not the hemosporidians, piroplasms, or gregarines. In the absence of adequate information concerning other species of the genus Dermocystidium, I propose retention of the name $D$. marinum for the present and postponement of any decision concerning where to place the oyster pathogen within the Apicomplexa. For the same reason, creation of a new genus and species for the oyster pathogen would be unwise at this time. The name Labyrinthomyxa marina (Mackin and Ray, 1966) should be rejected in the absence of any labyrinthulid characteristics (see reviews by Perkins, 1974 and Olive, 1975).

Much speculation surrounds the role of the apical complex, most workers agreeing that it acts in host cell penetration by some unknown mechanism (Scholtyseck, 1973; Aikawa and Sterling, 1974). The conoid does not appear to be necessary since some apicomplexan Protozoa such as Plasmodium spp. lack the organelle. The rhoptries and micronemes, however, appear to be of fundamental importance. They may contain lytic agents which, when released, cause localized breakdown of the plasmalemma, thus permitting penetration (Roberts et al., 1971; Jadin and Creemers, 1968; Hammond, 1971) or, more probably, may contain agents which induce phagocytosis of the parasite by the host cell (Jones et al., 1972; Trager, 1974). 
Attempts to characterize the contents of rhoptries and micronemes using cytochemical techniques have yielded conflicting results. Schrevel (1968) found acid phosphatase in rhoptry-like sacs associated with the digestive vacuole of a gregarine, Selenidium holandrei Vivier and Schrevel. The digestive vacuole arises from a pronounced invagination of the plasmalemma into the cell body via the conoid lumen. Such vacuoles have also been observed by Sheffield (1966) in the coccidian, Besnoitia jellisoni Frenkel, but no acid phosphatase determinations were made. Chains of small vesicles were seen in the conoid lumen of Toxoplasma gondii Nicolle and Manceaux by Vivier and Petitprez (1972) who suggested that the conoid might participate in both host cell penetration and intake of host cell materials. The same workers detected acid phosphatase in a few rhoptries, and polysaccharides were detected in both rhoptries and micronemes using the techniques of Thiéry (1967). They considered the latter observation to be evidence that rhoptries and micronemes are similar structures in different stages of development. Light microscope studies by Norrby et al. (1968) also show that there is acid phosphatase activity, often at one end of the parasite or scattered throughout the cytoplasm, activity which drops upon penetration of host cells, then rises after establishment in the host cell. The results of Mehlhorn et al. (1974), however, indicate that no acid phosphatase or polysaccharide is found in the rhoptries and micronemes of Toxoplasma gondii, Sarcocystis tenella, Besnoitia jellisoni, or Frenkelia sp. with the possible exception of low levels of acid phosphatase on the outer surface of the delimiting membrane of rhoptries in Frenkelia sp. and S. tenella. Ultrastructural localization of alkaline phosphatase and ATP-ase in cyst stages of S. tenella indicated that neither enzyme was present in the micronemes and rhoptries (Mehlhorn, 1975).

If polysaccharides are present in rhoptries and micronemes their significance is not known; however, the possible presence of acid phosphatase has been interpreted as further evidence that the apical complex is used in host cell penetration by delivery of lytic enzymes from the rhoptries and micronemes to the host plasmalemma.
$D$. marinum differs from $T$. gondii as observed by Vivier and Petitprez (1972) in that no polysaccharides were detected in the rhoptries or micronemes. The oyster pathogen may be similar to $T$. gondii and S. holandrei in that acid phosphatase may be present in the rhoptries, assuming that the spheroidal inclusions in the conoid of $D$. marinum are fragmented rhoptries. If so, a hydrolytic role for the rhoptries is possible. Subsequent studies are needed to demonstrate whether the organelles contain agents which induce phagocytosis of the parasite by the host cell or agents which permit penetration of the plasmalemma.

The "subpellicular membrane" of the Apicomplexa was at first reported to be a granular zone beneath the plasmalemma; however, subsequent, higher resolution studies have shown that it is actually two unit membranes discontinuous at the anterior polar ring and posterior ring. In D. marinum the "subpellicular membrane" analogue is a thin, granular layer. Since all types of zoospore membranes were easily resolved in my preparations, it is unlikely that lack of adequate fixation or resolution yielded a thin granular layer rather than unit membrane substructure. The layer may be derived from unit membrane degradation in the living cell as evidenced by its continuity with the two flattened vesicles at the anterior end of the zoospore (Figs. 5, 16, 17). The possibility that the flattened vesicles are homologous to the "subpelicular membrane" must also be considered. They are in the appropriate subplasmalemmal position above the microtubules and terminate directly above the polar ring. In other Apicomplexa the "subpellicular membrane" is thickened anteriorly and bends downward to form the polar ring to which the subpellicular microtubules attach. The latter follow a course below the "subpellicular membrane."

The granular layer of $D$. marinum is arranged into a labyrinthine complex like the "subpellicular membrane" of Plasmodium spp. (Aikawa and Sterling, 1974). The "subpellicular membrane" has not been found organized as a labyrinth in other Sporozoa (Scholtyseck, 1973); however, as in other Sporozoa, the "subpellicular membrane" of Plasmodium spp. is comprised of two opposed unit membranes.

The conoid of D. marinum is similar to those of other Apicomplexa (Scholtyseck, 1973; 
Scholtyseck et al., 1970) except that the structure is open along one side rather than being a closed truncated cone as in the other Apicomplexa. The spirally coiled microtubules of the conoid are 17 to $26 \mathrm{~nm}$ in diameter as compared to 26 to $30 \mathrm{~nm}$ diameter for other Apicomplexa (Scholtyseck, 1973). There are about 18 conoid microtubules as compared to the 6 to 8 recorded by most other workers (Scholtyseck, 1973) and ca. 20 found by PorchetHenneré (1975) in her excellent study of negatively-stained Sacrocystis tenella Railliet conoids.

At the anterior end the conoid width is 0.13 to $0.25 \mu \mathrm{m}$ as compared to 0.15 to $0.4 \mu \mathrm{m}$ for other species; the posterior width is 0.18 to $0.34 \mu \mathrm{m}$ as compared to 0.2 to $0.53 \mu \mathrm{m}$ in others; and the length (not including the three microtubular extensions) is 0.57 to $0.96 \mu \mathrm{m}$ as compared to 0.08 to $4 \mu \mathrm{m}$. Other Apicomplexa do not have an extension of the conoid to which are attached micronemes as in D. marinum. The angle of inclination of conoid microtubules in the zoospores $\left(50^{\circ}\right.$ to $\left.88^{\circ}\right)$ overlaps the range recorded for other Apicomplexa $\left(70^{\circ}\right.$ to $\left.90^{\circ}\right)$; however, the angle of the latter organisms is usually the same within the conoid of a given species (Scholtyseck, 1973) not being a function of the region of the conoid as in $D$. marinum.

Observations of the changes which occur in the apical complex organelles during host cell penetration are being made. It is known that upon establishment in the host the apical complex and subplasmalemmal granular layer are lost as trophozoites are formed (Perkins, 1969). Micropores are retained and increase in number.

\section{ACKNOWLEDGMENTS}

The author gratefully acknowledges the excellent technical support of Mrs. Deborah DeBiasi, Miss Susan Fox, and Miss Peggy Peoples. Dr. Jay Andrews is thanked for providing uninfected oysters for experimental infections.

\section{LITERATURE CITED}

Atkawa, M., and C. R. Sterling. 1974. Intracellular Parasitic Protozoa. Academic Press, New York, 71 p.

Angelopoulos, E. 1970. Pellicular microtubules in the family Trypanosomatidae. J Protozol 17: $39-51$.
Bracker, C. E., AND L. J. LitTlefield. 1973. Structural concepts of host-pathogen interfaces. In R. J. W. Byrde and C. V. Cutting (eds.), Fungal Pathogenicity and the Plant's Response. Academic Press, New York, p. 159 317.

Craig, A. S. 1974. Sodium borohydride as an aldehyde blocking reagent for electron microscope histochemistry. Histochemistry 42: 141-144.

Dodge, J. D. 1973. The fine structure of algal cells. Academic Press, London, 261 p.

DuBoscQ, O. 1921. Labyrinthomyxa sauvageaui n.g. n.sp., protéomyxée parasite de Laminaria lejolisii Sauvageau. Compt Rend Soc Biol 84: $27-33$.

Grell, K. G. 1973. Protozoology. SpringerVerlag, New York, 554 p.

Gustafson, P. V., H. D. Agar, and D. J. Cramer. 1954. An electron microscope study of Toxoplasma. Am J Trop Med Hyg 3 : 1008-1021.

Hammond, D. M. 1971. The development and ecology of coccidia and related intracellular parasites. In A. M. Fallis (ed.), Ecology and Physiology of Parasites. University of Toronto Press, Toronto, p. 3-20.

Jadin, J. M., AND J. CReEmers. 1968. Ultrastructure et biologie des toxoplasmes intraérythrocytaires chez un mammifère. Acta Trop 25: 267-270.

JoNes, T. C., S. YeH, AND J. G. HIrsch. 1972. The interaction between Toxoplasma gondii and mammalian cells. J Exp Med 136: 11571172.

KazAMA, F. 1973. Ultrastructure of Thraustochytrium sp, zoospores. III. Cytolysomes and acid phosphatase distribution. Arch Mikrobiol 89: 95-104.

Levine, N. D. 1970. Taxonomy of the sporozoa. J Parasitol 56(Sect 2): 208-209.

- 1973. Introduction, history, and taxonomy. In D. M. Hammond and P. L. Long (eds.), The Coccidia. University Park Press, Baltimore, Maryland, p. 1-22.

Mackin, J. G. 1951. Histopathology of infection of Crassostrea virginica (Gmelin) by Dermocystidium marinum Mackin, Owen, and Collier. Bull Marine Sci Gulf and Caribbean 1: 72-87.

- 1962. Oyster disease caused by Dermocystidium marinum and other microorganisms in Louisiana. Publ Inst Marine Sci Univ Texas 7: $132-229$.

—, AND J. L. Boswell. 1956. The life cycle and relationships of Dermocystidium marinum. Proc Natl Shellfish Assoc 46: 112-115.

- AND S. M. Ray. 1966. The taxonomic relationships of Dermocystidium marinum Mackin, Owen, and Collier. J Invertebr Pathol 8: 544-545.

Madelin, M. F. 1966. The fungus spore. Proceedings of the 18th Symposium of the Colston Research Society. Butterworths, London, 338 p. 
MEнLноR, H. 1975. Elektronenmikroskopischer Nachweis von alkalishcer Phosphatase und ATP-ase in Cystenstadien von Sarcocystis tenella (Sporozoa, Coccidia) aus der Schlundmuskulatur von Schafer. Z Parasitenk 46: 95-109.

-, J. Senaud, and E. Scholtyseck. 1974. Etude ultrastructurale des coccidies format des kystes: Toxoplasma gondii, Sarcocystis tenella, Besnoitia jellisoni et Frenkelia sp.: distribution de la phosphatase acide et des polysaccharides au niveau des ultrastructures chez le parasite chez l'hote. Protistologica 10: $21-42$.

Norkby, R., L. Lindiolm, AND E. Lycke. 1968. Lysosomes of Toxoplasma gondii and their possible relation to the host cell penetration of toxoplasma parasites. J Bacteriol 96: 916919.

Olive, L. S. 1975. The Mycetozoans. Academic Press, New York, 252 p.

Perkins, F. O. 1969. Ultrastructure of vegetative stages in Labyrinthomyxa marina (= Dermocystidium marinum), a commercially significant oyster pathogen. J Invertebr Pathol 13: 199-222.

. 1974. Phylogenetic considerations of the problematic thraustochytriaceous-labyrinthulid-Dermocystidium complex based on observations of fine structure. Veröff Inst Meeresforsch Bremerh Suppl 5: 45-63.

- 1976. Fine structure of lower marine and estuarine fungi. In E. B. G. Jones (ed.), Recent Advances in Aquatic Mycology. Paul Elek Limited, London, p. 279-312.

$\longrightarrow$, AND R. W. MENZEL. 1967. Ultrastructure of sporulation in the oyster pathogen Dermocystidium marinum. J Invertebr Pathol 9: 205-229.

Pickett-Heaps, J. D. 1975. Green algae. Sinauer Associates, Inc., Sunderland, Massachusetts, $606 \mathrm{p}$.

Ponchet-Henneré, E. 1975. Quelques précisions sur l'ultrastructure de Sarcocystis tenella. I.
L'endozoïte (après coloration negative). J Protozool 22: 214-220.

Ray, S. M. 1954. Biological studies of Dermocystidium marinum, a fungus parasite of oysters. Rice Institute Pamphlet, Special Issue, Nov. 1954, p. 1-114.

Roberts, W. L., C. A. Speer, and D. M. HaMMOND. 1971. Penetration of Eimeria larimerensis sporozoites into cultured cells as observed with the light and electron microscopes. J Parasitol 57: 615-625.

RYLEX, J. F. 1969. Ultrastructural studies on the sporozoite of Eimeria tenella. Parasitology 59: $67-72$.

Scholtyseck, E. 1973. Ultrastructure. In D. M. Hammond and P. L. Long (eds.), The Coccidia. Eimeria, Isospora, Toxoplasma, and related genera. University Park Press, Baltimore, Maryland, p. 81-144.

H. Mehl.horN, ANd K. Friedhoff. 1970. The fine structure of the conoid of Sporozoa and related organisms. $\mathrm{Z}$ Parasitenk 34: 68-94.

Schrever, J. 1968. L'Ultrastructure de la recion antérieure de la grégarine Selenidium et son intérêt pour l'étude de la nutrition chez les sporozoaires, J Microscopie 7: 391-410.

SHEFFIELd, H. G. 1966. Electron microscope study of the proliferative form of Besnoitia jellisoni. J Parasitol 52: 583-594.

Sprague, V. 1954. Protozoa. In P. S. Galtsoff (ed.), Gulf of Mexico. Its origin, waters, and marine life. U. S. Fish Wildlife Serv. Fishery Bull. 89: 243-256.

Tние́nx, J.-P. 1967. Mise en évidence des polysaccharides sur coupes fines en microscopie électronique. J Microscopie 6: 987-1018.

Trager, W. 1974. Some aspects of intracellular parasitism. Science 183 : 269-273.

Vivier, E., ANd A. Petrtprez. 1972. Données ultrastructurales complémentaires morphologiques et cytochimiques sur Toxoplasma gondii. Protistologica 8: 199-221. 